\title{
Capítulo 17
}

\section{O lúdico na radioatividade: trabalhando com a Lei 10.639/03}

José Guilherme Martins Siqueira ${ }^{1}$

Romário Pereira da Costa ${ }^{2}$
Nathália Sayuri Tateno ${ }^{3}$

Priscila Afonso Rodrigues de Sousa ${ }^{4}$

Resumo: O objetivo deste trabalho é o desenvolvimento de um jogo sobre radioatividade, pela aplicação da lei 10.639/03 na disciplina de química. Sendo constituído de um tabuleiro e cartas que trabalham com a ancestralidade e o tempo de meia vida de material radioativo (carbono-14), o tabuleiro tem o formato da África, utilizado para trazer a ideia histórica e cartas com informações indispensáveis para a datação de fósseis. Resultando em um jogo que estimula a criticidade para além de revisão dos conceitos químicos, sendo um auxílio para outras disciplinas, pois também trabalha com conceitos que envolvem a história, matemática, abrindo o campo de conhecimentos dos alunos com a arqueologia. Este jogo lúdico vem como uma forma de abordagem que promova o interesse do aluno pelo divertimento, mas não deixa de lado a função educativa.

Palavras-chave: Ensino de Química. Ancestralidade. Interdisciplinar.

\section{Introdução}

$\mathrm{Na}$ educação básica a disciplina de química ainda é marcada por abordagens tradicionais, sem objetivar uma educação mais significativa que proporcione a

1 Universidade Federal de Goiás - UFG. Regional Catalão, Unidade Acadêmica Especial de Física e Química. Contato: guilhermejms22@hotmail.com

2 Universidade Federal de Goiás - UFG. Regional Catalão, Unidade Acadêmica Especial de Física e Química. Contato: romariop@live.com

3 Universidade Federal de Goiás - UFG. Regional Catalão, Unidade Acadêmica Especial de Física e Química. Contato: nathytateno@hotmail.com

4 Universidade Federal de Uberlândia - UFU. Campus Santa Monica, Instituto de Química. Contato: rodriguessousa41@hotmail.com 
formação cidadã. Mediante esta situação é necessário modificar a metodologia aplicada em sala de aula, possibilitando o contato dos alunos com diversos temas, mostrando a presença da química no cotidiano dos mesmos, assim como a contribuição desta para o desenvolvimento da sociedade.

A química enquanto Ciência que se desenvolveu a partir das necessidades apresentadas pelo homem, tem como objetivo possibilitar ao homem, através do conhecimento, aprimorar seu senso crítico para que atue como cidadão dentro da sociedade em que se encontra.

Neste sentido, a educação auxilia o indivíduo a compreender as questões sociais que assolam a sociedade. Entre as inúmeras questões passíveis de discussão dentro do ambiente educacional, está a preocupação com a situação do negro no Brasil, uma vez que nosso país possui em suas raízes uma herança africana pouco valorizada. Entre as inúmeras leis e diretrizes da educação que exigem a discussão sobre as questões étnicas brasileiras, encontra-se a lei 10.639 sancionada em 2003 e que torna obrigatório o ensino de História e cultura afro-brasileira e africana nas escolas de ensino fundamental e médio.

A lei 10.639/03 é pouco abordada na disciplina de química, visto que a maioria dos professores inferem que os temas advindos em conjunto com a lei devem ser abordados apenas nas disciplinas de história, artes e geografia.

Segundo as Orientações Educacionais Complementares aos Parâmetros Curriculares Nacionais - PCN+ Ensino Médio (Brasil, 2002) e PCNEM (BRASIL, 1999) a química pode ser contextualizada através de temas sociais presentes na vivência dos alunos ou em fatos históricos da sociedade, ressaltando as tradições culturais e fatos históricos, para se construir e reconstruir conhecimentos químicos significativos.

Salienta-se que através da interdisciplinaridade e considerando os conhecimentos prévios do educando, relacionando-os com conhecimentos a serem adquiridos (conhecimento cientifico), pode-se gerar o que é chamado de aprendizagem significativa:

É através da aprendizagem significativa que o aluno poderá fazer parte de sua cultura e, ao mesmo tempo, não ser subjugado por ela, por seus ritos, mitos e ideologias (MOREIRA, 2009).

Para se alcançar a aprendizagem significativa o uso de metodologias diferenciadas atua como ponte para que o professor entrelace conhecimento científico e ideias de senso comum. Neste contexto, Kishimoto (1994), aconselha o jogo enquanto atividade lúdica, uma vez que é uma ferramenta que possui duas funções: a lúdica e a educativa, as quais quando em equilíbrio auxiliam na compreensão do que está sendo trabalhado. 
Os jogos são indicados como um tipo de recurso didático educativo que pode ser utilizado em momentos distintos, como na apresentação de um conteúdo, ilustração de aspectos relevantes ao conteúdo, revisão ou síntese de conceitos importantes e avaliação de conteúdos já desenvolvidos (CUNHA; 2004).

Além disso, o jogo auxilia o professor a discutir conceitos que não seriam bem compreendidos com o uso de uma metodologia baseada apenas na teoria. Conceitos químicos, tais como os que envolvem o conteúdo de radioatividade geralmente são tidos pelos alunos como demasiadamente abstrato e desinteressante. O jogo seria, então, uma ferramenta que auxiliaria na criação de um clima adequado para a investigação e a busca de soluções referentes aos conceitos que envolvem a radioatividade, instigando o aluno, auxiliando na compreensão e desenvolvimento de seu senso crítico.

Observando a importância dos jogos enquanto atividade lúdica que auxilia na compreensão dos conteúdos químicos, o objetivo central deste trabalho foi o desenvolvimento de um jogo, com o propósito de aplicação da lei 10.639/03 na disciplina de química através da unidade de radioatividade.

\section{Desenvolvimento}

A Lei n ${ }^{\circ} .10 .639 / 03$ que se estende no artigo 26 da Lei de Diretrizes e Bases da Educação Nacional - (LDB/ nº. 9304/96) determina que:

Art. 26-A. Nos estabelecimentos de ensino fundamental e médio, oficiais e particulares, torna-se obrigatório o ensino sobre História e Cultura Afro-Brasileira.

Esta Lei que se encontra em vigor desde 2003, exige mudanças que não são simples, pois determina ao professor ir muito além de como se trabalhar os conteúdos abordados na escola, enfatizando temáticas da história e da cultura afro-brasileira e africana nas diferentes disciplinas, incluindo a química, que é uma ciência que se constituiu historicamente.

Diversos são os conteúdos químicos que podem ser utilizados para aplicação da lei 10.639 em sala de aula, destacando o conteúdo de radioatividade.

A química nuclear é de fundamental importância para se entender o comportamento do átomo na sua menor dimensão, mas também na relação cotidiana, pois os conceitos envoltos com a radioatividade são utilizados na área Médica durante o tratamento de doenças como o câncer e exames de raio X para produção de imagens internas de seres vivos. A radioatividade mostra sua relevância ímpar na arqueologia, com a datação de objetos pelo carbono-14, possibilitando 
a identificação da idade de um fóssil e consequentemente contribuindo para o entendimento da evolução humana.

Segundo Kotz (1999), a quantidade de carbono-14 manteve-se praticamente constante nos últimos 20.000 anos na natureza, sendo também constante nos seres humanos. Uma vez que no organismo de seres vivos possuem o carbono-14, um isótopo do carbono, com tempo de meia vida de 5730 anos, é possível identificar a idade de um fóssil através da quantidade de carbono-14 residual.

Pesquisas indicam que a África é o berço da humanidade e do desenvolvimento social. Tais estudos pontuam que todos os seres humanos evoluíram de um ancestral comum de origem Africana. Entretanto, historicamente o negro é inferiorizado e visto de forma negativa, sofrendo preconceito, tendo as menores oportunidades, sendo excluídos socialmente desde o período da colonização (SILVA, 2009; CAVALLEIRO, 2001, ANDRÉ, 2008).

A lei está em vigor há mais de doze anos e, ainda faltam iniciativas para a valorização da temática afro-brasileira, principalmente no ensino de ciências. Em relação ao Ensino de Química, alguns autores têm sugerido propostas para se trabalhar as temáticas advindas da lei nas salas de aula do ensino básico, tais como Ferreira (2009), Pinheiro (2009) e no âmbito acadêmico, Anna Benite (2011), Francisco Júnior (2008) e Guimes Rodrigues (2010).

Pesquisadores da área de educação como Munanga (2005), Silva (2007, 2010) e Moore (2007) discutem a discriminação racial em que os negros estão submetidos na sociedade, sobretudo na educação, principalmente quando são excluídos do sistema formal de ensino e assim consequentemente de outras esferas sociais.

A escola tem grande contribuição para que a lei seja apresentada de forma contextualizada em sala de aula através de um ensino mais relevante direcionado pelo professor, sendo este um elemento essencial em sua metodologia.

Soares (2008), indica a importância de se trabalhar a ludicidade no ensino de química, seja na forma de jogo, brinquedo ou brincadeira, para o desenvolvimento educacional, mas também colaborando para a cultura e entretenimento dos alunos.

De acordo com Kishimoto (1996), o uso do jogo na escola favorece o aprendizado pelo erro e estimula a exploração e resolução de problemas, pois como é livre de pressões e avaliações, cria um clima adequado para a investigação e a busca de soluções. O benéfico do jogo está nessa possibilidade de estimular a exploração em busca de resposta e em não se constranger quando se erra.

Russel (1999), em uma extensa revisão bibliográfica, descreve artigos que utilizam jogos para ensinar conceitos gerais em Química (massa, propriedades 
da matéria, elementos químicos e estrutura atômica, soluções e solubilidade), nomenclatura, química orgânica e instrumentação, fórmulas e equações químicas em um total de 73 artigos, que se distribuem entre apenas 14 autores.

Ainda segundo Soares (2008), jogos no ensino de química vem se popularizando nos últimos anos. De acordo com Soares (2004), trabalhos ausentes na revisão de Russel (1999), exibem jogos relacionados aos conceitos de ácidos e bases e, também, há um jogo de tabuleiro para se discutir tabela periódica. No entanto não há nenhum jogo sobre radioatividade relatado nesta revisão bibliográfica, indicando a necessidade de estudos e produção de jogos educativos nessa área da química.

Geralmente quando o conteúdo de radioatividade é abordado se discute os benefícios e malefícios da radiação, sendo trabalhado documentários tais como a explosão de bombas atômicas em Hiroshima e Nagasaki; a explosão do reator da usina de Chernobyl; e a contaminação por césio-137, em Goiânia, sendo esse último mais relevante para a discussão, por compreender a grandeza social gerada pelo césio-137 no estado de Goiás. Tal tema se bem trabalhado possibilita o estimulo do senso crítico dos alunos e consequentemente uma aprendizagem mais significativa.

Uma outra proposta de abordagem do tema radioatividade relaciona-se com as análises envoltas com o carbono-14. Sabe-se que a origem da humanidade se deu na África, fato comprovado através do descobrimento de um crânio que foi datado pelos cientistas como o mais antigo já descoberto (TURATTI, 2008). Para realizar tal afirmação foi necessário a utilização da química nuclear para a realização da datação deste material fóssil, através da quantificação do carbono-14. Tal descoberta propicia o debate da química em função da lei 10.639/03, ao se discutir a ancestralidade e sua descoberta cientifica, direcionando a química para um ensino mais crítico e significativo.

Sendo assim, este trabalho tem por objetivo produzir material didático que sirva de auxílio para o professor em sala de aula, através da elaboração de um jogo lúdico que aborde o conteúdo químico radioatividade, contemplando a lei 10.639/03 ao se abordar a datação de fósseis utilizando carbono-14. O jogo tem como função estimular o senso crítico daqueles que entrarem em contato com tal material, propiciando uma aprendizagem mais significativa, pontuando o conceito de ancestralidade pelo ensino de química. $\mathrm{O}$ jogo foi elaborado pelo grupo de Pesquisas em Educação Química do Curso de Química da Universidade Federal de Goiás, Regional Catalão, tendo por base o projeto “A Lei 10.639/03 e o Ensino de Química.” 


\section{Metodologia}

Ao se iniciar a elaboração de um jogo lúdico que contemple os devidos aspectos é necessário ponderar a ênfase na investigação, onde os alunos são colocados em situação de realizar pequenas pesquisas, combinando simultaneamente conteúdos conceituais e atitudes (Pozo, 1998). Esse tipo de abordagem possibilita que o aluno desenvolva as três categorias de conteúdos procedimentais: habilidades de investigar, manipular e comunicar (Pro, 1998). Com respeito à comunicação, Gil Pérez (1996) enfatiza que não se trata de olhar para os alunos como cientistas profissionais quando estes são estimulados a comunicar seus resultados por meio de uma orientação socioconstrutivista que visa à promoção da aprendizagem em ciências.

O jogo desenvolvido pelo Grupo de Pesquisa tem como estrutura um tabuleiro, cartas e um dado. O objetivo a ser alcançado pelo jogo estaria em cada carta, pois a partir destas seria necessário estimar o tempo do fóssil e inserir no período correto do tabuleiro. Para isso, é preciso que o aluno compreenda os conceitos básicos da radioatividade como: desintegração, partículas alfa, beta e gama, cálculos de meia vida, além de compreensão dos períodos históricos e da evolução do homem.

O tabuleiro (Figura 17.1) com o formato da África traz a ideia histórica a ser abordada, ou seja, os alunos compreenderiam que os primeiros homens surgiram na região do continente africano e que aquela região contribuiu para a evolução da sociedade e consequentemente da ciência química; as casas do tabuleiro se dividem em períodos da pré-história e um posterior denominado contemporâneo (após a pré-história), como demonstrado na Tabela 17.1.

Tabela 17.1 Tabela de períodos históricos do jogo.

\begin{tabular}{|l|l|}
\hline \multicolumn{1}{|c|}{ Período } & \multicolumn{1}{c|}{ Anos aproximados } \\
\hline Período da Pedra Lascada & $>10.000$ a. C. \\
\hline Período da Pedra Polida & 10.000 a 5.000 a. C. \\
\hline Idade dos Metais & 5.000 a 4.000 a. C. \\
\hline Contemporâneo & 4.000 a. C. até a atualidade \\
\hline
\end{tabular}




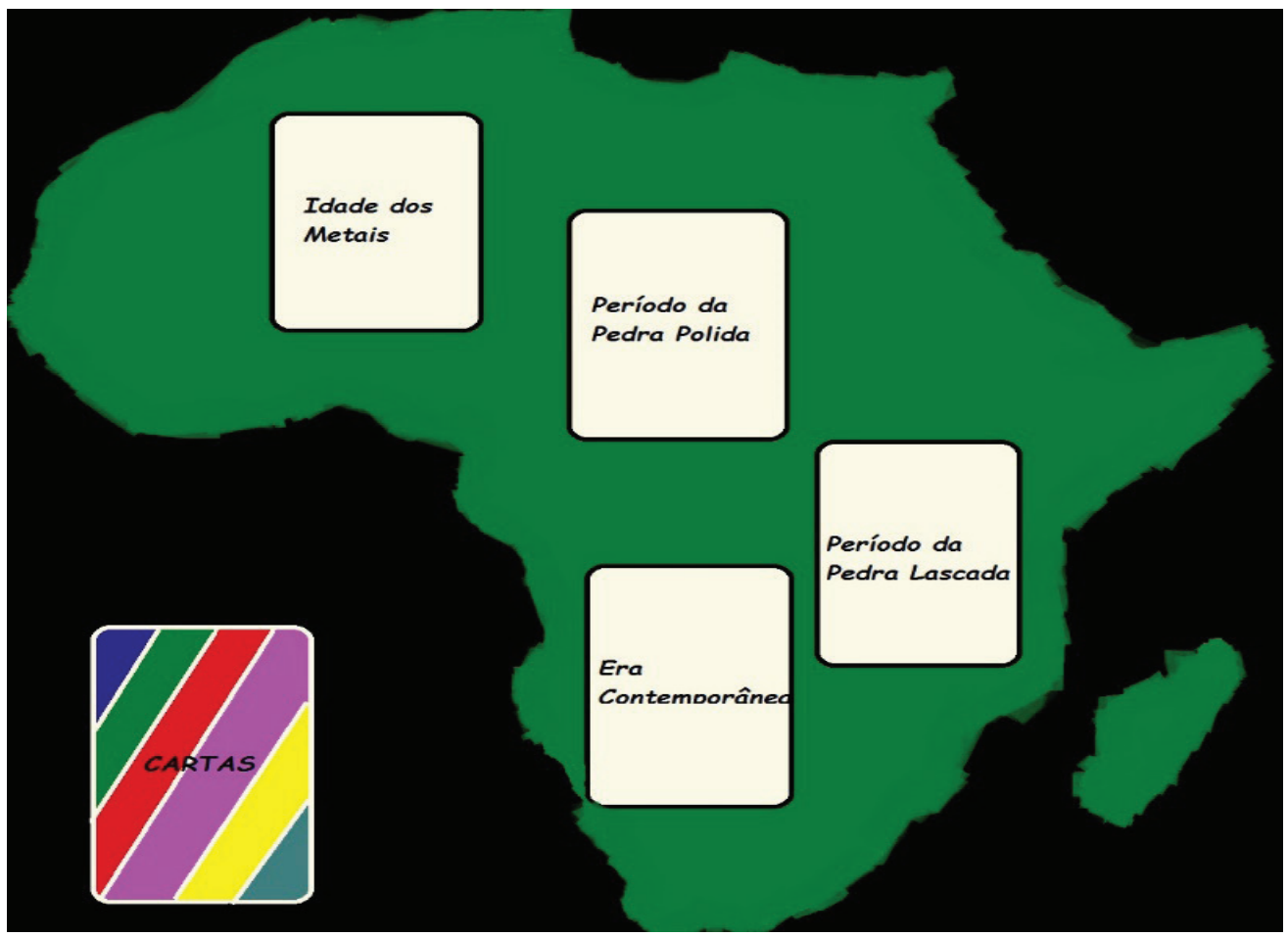

Figura 17.1 Tabuleiro desenvolvido pelo grupo de pesquisa Educação Química para o jogo de radioatividade abordando a lei 10.639/03

Fonte: Acervo pessoal (2016).

As cartas com imagens dos fósseis contêm informações necessárias para a datação pelo carbono-14, estimulando o lado investigativo do aluno, que deveria associar história, imagem, informação e conceito químico. As informações a respeito do fóssil auxiliam na identificação de qual período ele pertence, desta forma cada carta terá sua casa adequada no tabuleiro.

Em uma posterior aplicação seria levado vários tabuleiros com suas cartas para a turma que entraria em contato com a atividade lúdica. Os alunos seriam divididos em grupos de 4 a 6 alunos que teriam a tarefa de estimar o período onde viveu o fóssil da carta que está em sua mão. Cada aluno pegaria uma carta por vez e por meio das informações disponíveis, determinaria o tempo que levou para o carbono-14 chegar aquela quantidade por meio de simples cálculos matemáticos, possibilitando que tal carta seja colocada na sua casa correspondente no tabuleiro, trabalhando assim a ideia de evolução e o conceito de ancestralidade, pois as cartas se baseiam na construção social e evolucionária, havendo cartas a respeito do crânio mais antigo já datado, passando pelo período das navegações, pela 
escravidão, até chegar nos dias de hoje. Não objetivando desta forma a competitividade para um ganhador, mas sim a construção histórica por meio da criticidade.
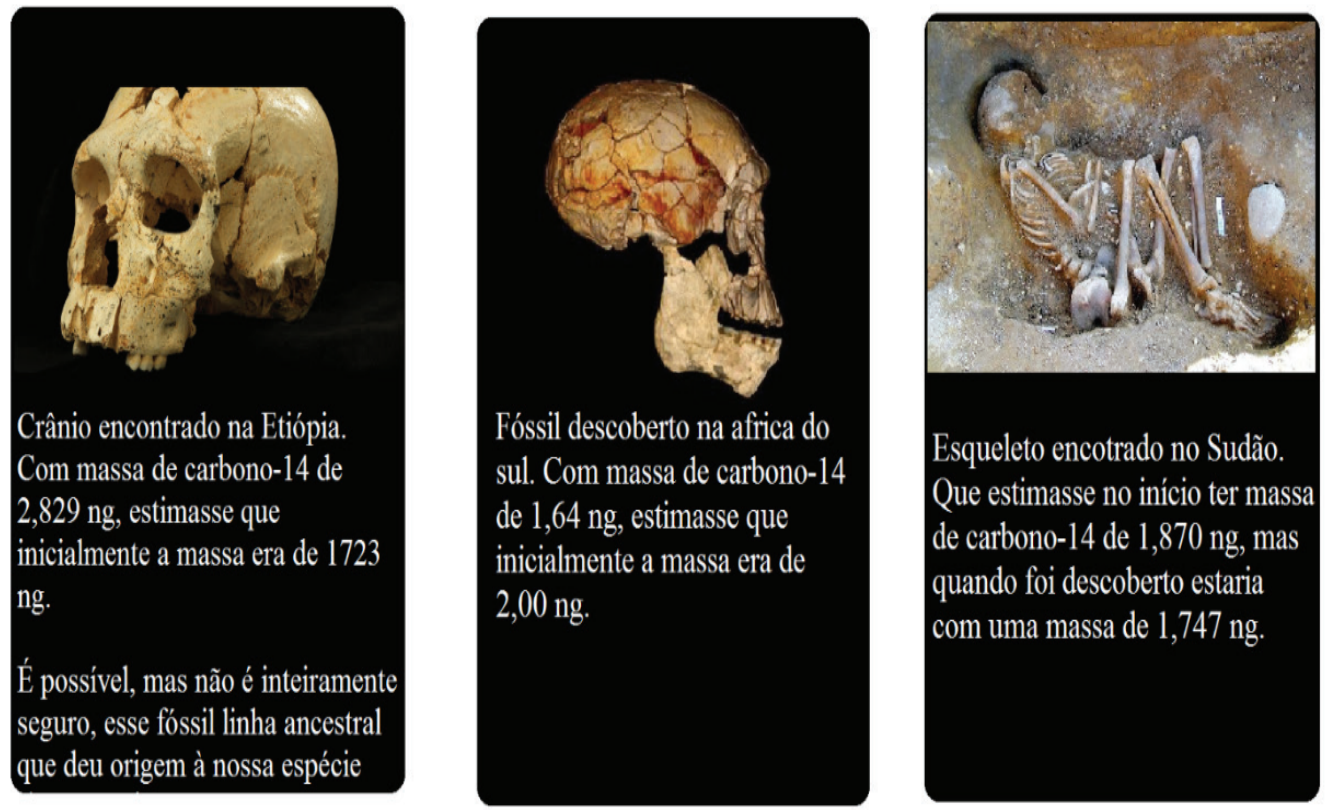

Figura 17.2 cartas desenvolvidas pelo grupo de pesquisa Educação Química para o jogo de radioatividade abordando a lei 10.639/03

Fonte: Acervo pessoal (2016).

O tabuleiro foi impresso em papel cartão para conferir mais resistência ao mesmo, as cartas (figura 17.2) impresso em folhas A4 e recortados com o seu formato, nas quais estariam contidas as seguintes informações: $\mathrm{O}$ local onde o fóssil foi descoberto, a quantidade de carbono-14 inicial, isso é, a quantidade estimada de carbono-14 no momento em que o ser vivo morreu e a quantidade de carbono-14 final, o do momento que ele foi descoberto por arqueologia, pensada essas informações para facilitar o cálculo de meia-vida e estimar a idade desse fóssil. Essas cartas totalizam 40 unidades.

Assim com o tabuleiro e as cartas, a turma seria dividida em grupos, iniciando com os alunos jogando o dado para se decidir quem começaria e qual seria a ordem de cada aluno a pegar as cartas. Ao pegar a carta o aluno tem que por meio das informações dizer em qual período o fóssil pertence, se errar este jogador ficara a próxima rodada sem participar, as respostas estarão com o professor, e este terá o papel de conferir a resposta dada pelo aluno. O ganhador será aquele que ao final de todas as cartas tiver mais acertos. 


\section{Discussão e resultados}

A necessidade de se trabalhar com a lei 10.639/03 na educação básica é de extrema importância, sendo o ensino de química uma das formas de abordagem, pois possibilita através dos diferentes conteúdos a construção histórica, indo além ao proporcionar um ensino de química mais relevante para a construção crítica do aluno.

Ao se trabalhar com a radioatividade é possível ter contato com o conceito de ancestralidade, pois no movimento negro o ancestral é visto como uma figura que possui significado relevante. Estas pessoas deixaram as suas marcas na resistência contra a opressão dos dominadores, com os saberes tecnológicos, e com os preparos de determinados medicamentos populares que ainda são preparados e utilizados pelos seus descendentes. Segundo Guillen (2013):

"Os ancestrais foram aqueles, homens ou mulheres, que viveram uma vida exemplar e nesse sentido, têm desempenhado um importante papel para muitos militantes do movimento negro. São pessoas de referência para as labutas cotidianas, que lutaram e resistiram no passado, e que servem, portanto, de exemplo para os que lutam na atualidade. Proporcionam ânimo na luta, coragem e determinação para levar adiante a tarefa cotidiana de combater o racismo e propor uma sociedade mais justa para negros e negras no Brasil. São pessoas em quem se espelhar” (p. 1-2).

Desta forma a história da África também se faz pelos achados arqueológicos, indicando, assim, que a química por meio de suas técnicas de análise, tem saliente contribuição. De tal modo se insere a chamada arqueometria, que são as análises de absorção atômica, espectrometria, difração e fluorescência de raios X, microscopia, análise por ativação de nêutrons, bem como a datação do carbono-14 (ISKANDER, 2010). Possibilita-se, então, trabalhar tal temática no ensino de química através do conteúdo de radioatividade, por meio do jogo lúdico que estimula os valores civilizatórios afro-brasileiros: territorialidade, corporeidade, cooperativismo, energia vital, memória, ancestralidade. Segundo Lody (1992):

"Para o mundo cultural afro-brasileiro o dendê é marca, distintivo e atestação da memória, da ação, da produção, criação e recriação de um patrimônio de bases africanas absorvido, e também reinventado em espaço brasileiro, (p. 1)."

Desta forma o jogo lúdico motiva por meio do seu caráter não competitivo a cooperação entre os alunos para a construção histórica e a retomada da figura de ancestralidade para a sua construção sócio-histórica advinda da África. 


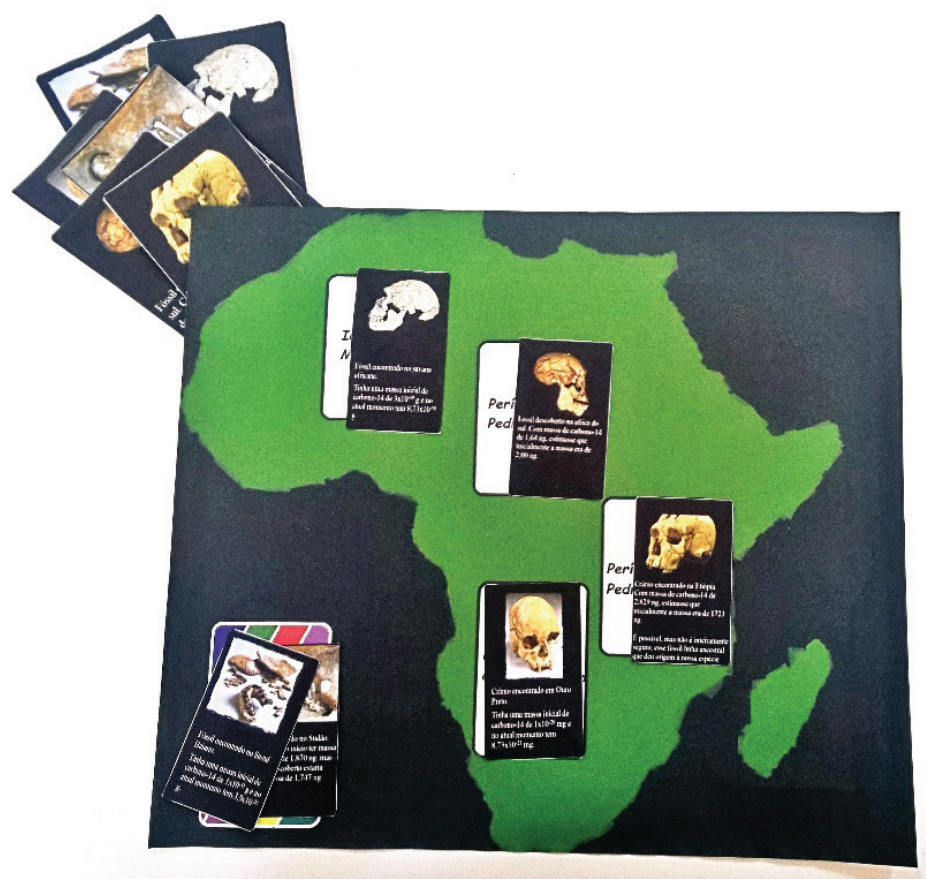

Figura 17.3 jogo de radioatividade abordando a lei 10.639/03

Fonte: Acervo pessoal (2016).

Ao se trabalhar na criação deste jogo (Figura 17.3) o licenciando se constitui de forma mais abrangente para atuar em sala de aula, já que na maioria das vezes este não tem o menor contato com essa lei, assim sendo este jogo é a oportunidade para o licenciando se debruçar a respeito dela. A construção de um jogo que permite trabalhar a criticidade no ensino médio, contribuindo para a sua atuação dentro de sala de aula ao começar a exercer sua profissão, também sendo a oportunidade de abrir visão para a aplicação da lei 10.639/03. Assim é relevante em sua formação trabalhar com a ludicidade e a esta lei, uma vez que é uma forma eficaz para um ensino mais significativo.

Entretanto para a construção deste jogo se observou a dificuldade de relacionar a química com essa lei, visto que é necessário buscar uma relação que aprofunde a química, saindo da superficialidade. Assim, necessita- se da interação da química não apenas com a história, mais com questões sociais, matemáticas e biológicas, por isso na constituição do jogo há a procura para essa abordagem, tornando o ensino de química mais interdisciplinar.

Salienta-se que este jogo vai além da revisão dos conceitos de radioatividade, sendo também importante no auxílio de outras disciplinas, pois também trabalha 
com conceitos que envolvem a história, matemática, abrindo o campo de conhecimentos dos alunos com a arqueologia, que tem a química como uma das suas aplicações. Deste modo o jogo lúdico vem como uma forma de abordagem que promove o interesse ao aluno pelo divertimento, mas não deixa de lado a função educativa, pois para jogá-lo é necessário o conhecimento químico, e ao decorrer do jogo é necessário a criticidade do aluno para seu entendimento.

\section{Considerações finais}

Observa-se atualmente uma nova realidade na educação básica brasileira. A ênfase aos conteúdos sobre a história da África e dos afrodescendentes exige mudanças na estrutura e nas concepções que permearam e ainda permeiam os educadores, considerando que no ensino ainda se privilegia a cultura ocidental europeia em detrimento das demais. Acredita-se que por meio de mudanças no ensino básico possibilite uma formação mais significativa, contribuindo para a formação de um cidadão com maior preocupação em termos sociais. Para isso o ensino de química é um meio de se alcançar a abordagem cultural, social e racial também relevante no cumprimento da lei 10.639/03, sendo o lúdico uma forma de unir o ensino de química a lei de forma divertida, que incentiva o aluno para essa reconstrução de saberes.

Robustece a importância de maior engajamento de pesquisadores sobre a aplicação da lei 10.639/03 no ensino de química para ser alcançado práticas escolares ativas na transmissão das noções inerentes à cultura afro-brasileira correlacionados ao ensino de química. Sendo importante o contato com a lei nos cursos de licenciatura, para a formação de professores que possam trabalhando incluindo a cultura afro-brasileira de forma relevante para uma sociedade mais justa, entretanto na formação de professores essa lei é pouco abordada, principalmente em cursos das extas e essa postura tem que começar a mudar.

\section{Referências}

ANDRÉ, M. C.; O Ser Negro - A construção da subjetividade em afro brasileiros. Brasília, LGE Editora, 2008.

BRASIL. Lei $\mathbf{n}^{\mathbf{0}}$ 10.639, de 9 de janeiro de 2003. Altera a Lei no 9.394, de 20 de dezembro de 1996, que estabelece as diretrizes e bases da educação nacional, para incluir no currículo oficial da Rede de Ensino a obrigatoriedade da temática "História e Cultura Afro-Brasileira”, e dá outras providências. Diário Oficial [da] República Federativa do Brasil. Brasília, DF, 9 jan. 2003. Disponível em: <http://www.planalto.gov.br/ccivil_03/leis/2003/L10639.htm>. Acessado de maio 2016. 
- Secretaria de Educação Média e Tecnológica - Ministério da Educação e Cultura. PCN + Ensino Médio: Orientações educacionais complementares aos Parâmetros Curriculares Nacionais. Brasília: MEC/SEMTEC, 2002.

BENITE, A. M. C.; SOUZA, E. P. L.; AlVINO, A. C. B. Ensino de Ciências e Identidade Negra: Estudos sobre a configuração da ação docente. In: VIII Encontro Nacional de Pesquisa em Educação em Ciências e I Congreso Iberoamericano de Investigación en Enseñanza de las Ciencias, 2011, Campinas. Anais do VIII Encontro Nacional de Pesquisa em Educação em Ciências e I Congreso Iberoamericano de Investigación en Enseñanza de las Ciencias. Rio de Janeiro: Abrapec, 2011.

CAVALLEIRO, E. Racismo e anti-racismo na educação. Repensando nossa escola. São Paulo: Summus, 2001.

CUNHA, M. B.: Jogos de Química: Desenvolvendo habilidades e socializando o grupo. Eneq, 2004.

FRANCISCO JÚNIOR, W.E. Educação antirracista: reflexões e contribuições possíveis do ensino de ciências e de alguns pensadores. Ciência \& Educação, v. 14, n. 3, 2008.

GIL-PÉREZ, D.; VALDÉS-CASTRO, P. La orientación de las prácticas de laboratorio como investigación: un ejemplo ilustrativo. Enseñanza de las Ciencias, v. 14, n. 2, 1996.

GUILLEN, I. C. M. Ancestralidade e oralidade nos movimentos negros de Pernambuco. Natal: Anais da ANPUH, 2013.

ISKANDER, Z. A Arqueologia da África e suas técnicas - Processos de datação. In: História geral da África, I: Metodologia e pré-história da África / editado por Joseph Ki -Zerbo. - 2.ed. rev. - Brasília: UNESCO, 2010. Disponível em: http://portaldoprofessor.mec.gov.br/storage/materiais/0000015104.pdf. Acessado em 28/05/2015

KISHIMOTO, T. M. O jogo e a educação infantil. São Paulo: Pioneira, 1994.

. O Jogo e a Educação Infantil. IN: Jogo, Brinquedo, Brincadeira e a Educação. KISHIMOTO, T. M. São Paulo: Cortez Editora, 1996. 
KOTZ, J.C.; TREICHEL Jr., P. Chemistry \& chemical reactivity. Nova Iorque: Saunders College Publishing, 1999.

LODY, R. Tem dendê, tem axé: etnografia do dendezeiro. Rio de janeiro: Pallas, 1992.

MOORE, C. Racismo e Sociedade: novas bases epistemológicas para entender o racismo. Belo Horizonte: Massa Edições, 2002.

MOREIRA, M. A., Aprendizagem Significativa Crítica. Disponível em: www. if.ufrgs.br/ moreira/apsigcritport.pdf. Acesso em 13 de jun de 2009.

MUNANGA, K. (org). Superando o racismo na escola. Brasília: Ministério da Educação, Secretaria de Educação Continuada, Alfabetização e Diversidade, 2005.

PINHEIRO, J. S. Aprendizagens de um grupo de futuros(as) professores(as) de química na elaboração de conteúdos pedagógicos digitais: em face dos caminhos abertos pela lei federal $n^{\circ} 10.639$ de 2003. 202 f. 2009. Dissertação (Mestrado em Química)- Universidade Federal de Uberlândia, Uberlândia, 2009.

POZO, J. I. (Org.). A solução de problemas. Porto Alegre: Artmed, 1998.

PRO, A. Se pueden enseñar contenidos procedimentales en las classes de ciencias? Enseñanza de las Ciencias, 1998.

RODRIGUES FILHO, G.; MOREIRA, P. F. S.; Fusconi, R.; Jacobucci, D. F. C. A bioquímica do candomblé - Possibilidades didáticas de aplicação da lei federal 10.639/03. Química Nova na Escola (Impresso), 2011.

RUSSELL. J. V. Using games to teach chemistry- an annotated bibliography. Journal of Chemical Education, 1999.

SILVA, D. V. C.; SILVA, P. B. G. E. Cidadania, Relações Ético-raciais e Educação: Desafios e Potencialidades do Ensino de Ciências. Educação e Pesquisa, São Paulo: USP, 2010.

SILVA, M. L. Ciência, raça e racismo na modernidade. Santa Cruz do Sul: EDUNISC, 2009. 
SILVA, P. B. G. E. Aprender, ensinar e relações étnico-raciais no Brasil. Porto Alegre: Educação, 2007.

SOARES, M. H. F. B. Jogos e atividades lúdicas no ensino de química: teoria, métodos e aplicações. In: ENCONTRO NACIONAL DE ENSINO DE QUÍMICA. Curitiba: UFPR, 2008.

. O lúdico em Química: jogos e atividades aplicados ao ensino de Química. Universidade Federal de São Carlos (tese de doutorado, 2004).

TURATTI, M. C. M. O povo de Luzia- em busca dos primeiros americanos. Cadernos de campo, São Paulo, n. 17, p. 317-319, 2008. 